\title{
O ensino da língua inglesa e o uso das tecnologias nas perspectivas da análise do discurso pecheuniano e da psicanálise.
}

\author{
Michele Ester de Moura Campos Furlan \\ Universidade Federal de Mato Grosso do Sul
}

\begin{abstract}
Resumo
Este artigo visa a discutir o uso das novas tecnologias nas práticas de ensino por meio de análise dos discursos de professores de língua inglesa, os quais são permeados por discursos científicos e tecnológicos que o legitimam como estatuto de verdade. O corpus é constituído por trechos de três ensaios escritos por professores que lecionam em diferentes realidades de ensino: em uma escola livre de idiomas, em uma escola particular de ensino fundamental e médio e em uma escola pública, também de ensino fundamental e médio. A pesquisa se baseia nos pressupostos teóricos da Linguística Aplicada, da Análise do Discurso (Pêcheux, 1990) e da psicanálise lacaniana. Os resultados mostraram que o professor de língua estrangeira se vê em uma situação de conflito, pois, aceita e acredita que o uso das novas tecnologias auxiliará na eficácia dos resultados do seu trabalho, mas enfrenta dificuldades para colocá-los em prática e inovar no que diz respeito aos procedimentos e métodos pedagógicos de ensino. É um professor que busca sua completude ao mesmo tempo em que ainda faz uso do convencional e do tradicional, mas que, mesmo assim, constrói um discurso pautado na cientificidade, a qual o legitima e constitui sua identidade de professor.
\end{abstract}

Palavras-chave: Linguística Aplicada, Ensino, Identidade.

\begin{abstract}
This article aims to discuss the use of new technologies in teaching practices through the analysis of English language teachers' discourse, which is permeated by scientific and technological discourses that legitimize the status of truth. The corpus consists of three sections of essays written by teachers who teach in different realities: in a language school, in a private school and in a public school, both for secondary and high school. The research is based on theoretical assumptions of Applied Linguistics, Discourse Analysis (Pecheux, 1990) and Lacanian psychoanalysis. Results showed that foreign language teachers find themselves in a conflicting situation. On the one hand, they accept and believe that the use of new technologies will aid in the effectiveness of the results of their work, but, on the other hand, they face difficulties putting new technologies into practice, and, at the same time, innovating in teaching methods. It is picture of teachers who seek fulfillment without abandoning the traditional, although they build a scientific discourse, which legitimizes and constitutes their identity as teachers.
\end{abstract}

Keywords: Applied Linguistics, Education, Identity. 


\section{INTRODUÇÃO}

O sistema educacional sempre se viu atrelado às teorias científicas e ao uso das tecnologias. Mais recentemente, com o advento do computador e da internet, essa relação com as práticas escolares se estreitou, uma vez que esses aparatos tecnológicos estão presentes em todos os âmbitos sociais fazendo parte do cotidiano das pessoas. Até há pouco tempo, as pesquisas mostravam que mantinham uma relação dialética de amor e ódio na medida em que o professor reconhecia a importância dos avanços científicos e tecnológicos para o desempenho de seu trabalho, mas, o rejeitava e o envolvia de críticas negativas (CORACINI, 2007). No entanto, aparelhos eletrônicos como televisão, $C D$ player, computador, celular, tablet, $D V D$, e a própria internet, estão tão inseridos na sociedade que é quase impossível nos vermos em atividades de trabalho, estudo ou lazer sem que um desses aparatos tecnológicos não esteja presente.

Avanços tecnológicos causam mudanças significativas na vida das pessoas, principalmente quando as afetam diretamente. Dentre estas, podemos destacar: uma mudança radical na maneira de as pessoas se relacionarem visto que a interação é constante; uma mudança do fluxo de informações uma vez que a velocidade de difusão se torna mais rápida; e uma mudança quanto à exposição de intimidade das pessoas, a qual se relaciona com as duas mudanças anteriores. Hoje, muitas vezes, ouvimos por meio da mídia, que os analfabetos digitais estão fadados a não conseguir emprego e são, muitas vezes, marginalizados. Basta olharmos a nossa volta e veremos a quantidade de pessoas com seus smartphones, conectados a internet vinte e quatro horas por dia. Obviamente que não seria diferente na escola, no ensino. Cada vez mais se torna imprescindível o uso de tecnologias em sala uma vez que a sociedade se torna cada vez mais digital, e essa sociedade digitalizada é dinâmica, é cada vez mais cedo exposta ao seu uso e, consequentemente, mais dependente dela fica. Mas, é importante salientar que os desafios se apresentam na mesma medida de sua revolução, ou seja, são enormes. Um país continental como o Brasil, em que a disparidade socioeconômica é também tão diversa quanto suas distâncias, em que problemas estruturais das escolas aparecem todos os dias nos noticiários, em que os professores são mal preparados, ganham baixos salários e estão desmotivados, fazer com que a tecnologia seja implantada em sala de aula uniformemente é quase algo utópico. Estariam as novas tecnologias realmente inseridas nas práticas educacionais? Estariam elas alterando as abordagens de ensino de língua estrangeira? Será que os professores utilizam-se dessas 
tecnologias em sala de aula? E como estariam os discursos sobre tecnologia permeando a identidade do professor? Coracini (2007) investigou redações de professores da rede estadual de ensino do estado de São Paulo, escritas no ano de 1997, e constatou que existia uma situação de conflito no imaginário do professor, despertando, ao mesmo tempo, o desejo de dominar essas tecnologias e a angústia diante da constatação de seu desconhecimento e das dificuldades que colocam em xeque sua autoridade ou poder legitimado pelo saber que, embora lhe seja ainda atribuído pelo imaginário social, se vê questionado. Os professores temiam que as máquinas pudessem substituí-los. E agora, no ano de 2015, dezoito anos depois, será que poderemos chegar à mesma conclusão? Essas são algumas questões que pretendo discutir ao longo desse artigo.

Para tanto, foram utilizados como corpus parágrafos de ensaios escritos por professores de língua inglesa sobre o uso das novas tecnologias e as práticas escolares. Selecionamos trechos de diferentes realidades: de um curso livre de inglês, de uma escola particular de ensino fundamental e médio e de uma escola pública estadual, também de ensino fundamental e médio, para determinar se existe diferença entre uma realidade e outra, averiguar como acontece o uso da tecnologia pelos professores de língua inglesa e analisar como se dá essa relação, a fim de, por meio de seus discursos, mostrar a construção da sua identidade. Todos os professores lecionam na cidade de Três Lagoas, no estado do Mato Grosso do Sul, Brasil.

Baseamo-nos, para esse artigo, nos pressupostos teóricos da Linguística Aplicada a qual estuda métodos e abordagens de ensino de língua estrangeira bem como o relaciona com a prática; da Análise do Discurso, que postula o interdiscurso como o lugar em que estão presentes todos os discursos acerca de determinado assunto e que farão parte da formação discursiva (PÊCHEUX,1990); e da psicanálise Lacaniana que problematiza o sujeito como heterogêneo e cindido, constantemente em busca de sua completude e de sua identidade, a qual se apresenta como constitutiva desse sujeito que busca incessantemente o estatuto da verdade absoluta.

Refletindo sobre a identidade do professor é que esse artigo objetiva discutir o uso das tecnologias nas práticas de ensino por meio de análises dos seus discursos, os quais são permeados por discursos científicos e tecnológicos que o legitimam como estatuto de verdade.

Hipotetizamos que, apesar de ainda estar dividido entre os benefícios e as críticas, o uso das tecnologias como práticas em sala de aula caminha para a normatização, ou seja, está inserido no cotidiano escolar e os professores utilizam essas 
tecnologias sem grandes dificuldades ou estranhamentos.

\section{LINGUÍSTICA APLICADA, ENSINO E O USO DAS TECNOLOGIAS}

Ao longo dos anos, diferentes métodos e abordagens se sucederam como tentativas de sistematizar o ensino da língua estrangeira. Segundo Leffa (1988, p. 211 213), na história do ensino de línguas existem registros de métodos a partir do Renascimento, quando surge interesse pelas culturas Grega e Latina, destacando-se o método Gramática e Tradução (AGT), o qual ensina a segunda língua pela primeira, e o Método Direto, cujo princípio fundamental é ensinar a língua estrangeira pela língua estrangeira. Nesse momento, o ensino de línguas utilizava somente o livro, principalmente as gramáticas. Nos anos de 1930, os soldados americanos necessitavam aprender rapidamente uma língua estrangeira, por causa da Segunda Guerra Mundial, e foi desenvolvido pelos linguistas, com base em fundamentos da psicologia (Behaviorismo), o método Audiolingual cuja metodologia utilizava exercícios de repetição e substituição, as aulas eram focadas no método e no professor, os erros corrigidos prontamente para que não afetassem negativamente o processo de aprendizagem e o aluno era visto como uma tábula rasa que necessitava ser moldada. Foram introduzidos, para eficácia desse método, áudios de conversas entre nativos e vídeos com situações reais, para que os alunos pudessem repetir e assim aprimorar sua fala. Imitando um nativo, minimizariam os efeitos negativos do professor, sua pronúncia e entonação. É importante destacar que, nesse momento, o sujeito é visto como cartesiano, como homogêneo e dono de si, de seu discurso e de seu saber. Possui o controle da situação e de sua fala e tem, na centralização da figura do professor, uma marca de sua autoridade.

Começam a surgir, principalmente na Europa, estudos semânticos e sociolinguísticos, que enfatizavam o estudo do discurso que pressupunha não apenas a análise do texto, mas também, as circunstâncias em que o texto era produzido e interpretado. Para Cardoso (2005, p. 32),

A língua é uma entidade abstrata, formal, enquanto o discurso é um lugar de investimentos sociais, históricos, ideológicos, psíquicos, por meio de sujeitos interagindo em situações concretas de discurso por intermédio da língua (mas aprendem a língua por meio de situações concretas de discurso) e cada discurso acaba por se constituir um universo semântico específico. 
Nesse novo contexto, surge a Abordagem Comunicativa cuja ênfase está não na forma, mas na comunicação. As formas são ensinadas apenas quando necessárias para desenvolver a competência comunicativa. A língua é ensinada tendo como guia suas funções. Concomitantemente, o computador e a internet se espalham pelo mundo globalizado e cada vez mais se fazem presentes na vida das pessoas. Ferramentas e softwares são desenvolvidos para auxiliar o ensino de línguas estrangeiras. O usuário passa de exercícios artificiais a situações linguísticas reais de comunicação até ser produtor de conteúdo. No entanto, segundo Paiva (no prelo, p. 9), "grande parte desse material continua com foco exclusivo na forma."

Atualmente, tanto os estudos sobre aprendizagem de língua estrangeira quanto a relação do homem com o computador vêm mudando. Os estudos recentes apontam para o fato de que não existe a metodologia correta, a abordagem verdadeira. O que determinará o sucesso no processo de aquisição de uma língua estrangeira é uma série de fatores de diversas ordens: sociais, pessoais, de personalidade, motivação, experiências vividas, necessidades pessoais e profissionais, fatores emotivos, dentre outros. De acordo com Paiva (2011 p. 74), "podemos entender a língua como um sistema dinâmico não linear e adaptativo, composto por uma conexão de elementos biocognitivo-sócio-histórico-culturais e políticos que nos permite pensar e agir em sociedade." Da mesma forma, os recursos da web oferecem ao aprendiz aparatos tecnológicos que lhe permite, efetivamente, usar a língua em experiências diversificadas de comunicação. Pela primeira vez o aprendiz passa a ser autor, pode publicar seus textos e interagir com recursos textuais, acrescidos de áudio e vídeo. (PAIVA, no prelo, p. 11)

Essa nova visão, bem como a relação que o homem mantém atualmente com o computador, vem ao encontro da concepção de sujeito atualmente vigente. Entendemos que o homem não é homogêneo, mas sim, heterogêneo e cindido, que falha e que transita constantemente entre o Um, ou seja, a língua materializada, e o Não um, isto é, o inconsciente (ALTHIER-REVUZ, 1998). Isso tanto para o professor quanto para o aluno, que estão sempre em busca de sua completude.

Para Coracini (2007, p. 41), o sujeito é considerado "cindido, inconsciente, descentrado ao qual, portanto, escapa o controle de si, de seus atos e pensamentos, dos efeitos de sentido de seu dizer." E, por isso, se opõe ao sujeito do estruturalismo, ou seja, um sujeito dono de seu dizer. E é justamente esse professor em busca de sua completude enquanto pessoa e enquanto profissional, que está constantemente se 
questionando, se autoavaliando, buscando ser o professor que está constituído no seu imaginário, o qual permeia seu discurso.

Com relação ao discurso, nós o consideramos como heterogeneamente constituído, ou seja, é atravessado por fragmentos de outros discursos e que são manifestações da memória discursiva, de outros dizeres que nos precedem e que nos constituem como sujeitos. Para Cardoso (2005, p. 35) "tanto o sujeito como o sentido do discurso não são dados a priori, mas, são constituídos nos interior dessas formações discursivas," as quais podem ser definidas como "grandes unidades históricas que os enunciados constituem" (Id. Ibid.).

Encontramos na constituição de um discurso didático-pedagógico fragmentos de muitos outros discursos como o do governo, o da ciência, o da mídia, o dos pais, o dos alunos e o da própria instituição escola, por exemplo, todos colaborando, dessa forma, para a construção da identidade desse professor. O que nos chama a atenção é que dentre todos esses discursos que formam o discurso didático-pedagógico, o discurso científico se constitui como aquele que agrega valor de verdade ao dito. Dessa forma, Coracini (2003 p. 85) afirma que no contexto da (pós-)modernidade, apesar de o cientista se alimentar de certezas, do ideal de um dia alcançar a verdade absoluta, ele se depara com a angústia da incerteza, da contingência e que essa verdade não passa de metáforas que procuram preencher a falta. São, dessa forma, remédio e veneno (DERRIDA 1972/1991), uma vez que parecem trazer a solução para todos os problemas e, no entanto, na prática, acabam por concretizar-se como um amontoado de ilusões, e nesse sentido, a concepção de identidade também pode ser considerada ilusória, pois, segundo a psicanálise lacaniana, ela só existe como construção imaginária.

\section{ANÁLISE DOS DADOS}

O primeiro trecho foi escrito por uma professora de um curso livre de inglês.

Acredito que para o ensino de línguas a utilização de alguns equipamentos é fundamental, pois, agrega prática dinâmica à teoria.

Utilizo recursos de áudio, em 100\% de minhas aulas. CDs com falantes nativos, ou músicas para exercícios de áudio são recursos que utilizo para tentar desenvolver as habilidades de compreensão da L2 com a qual trabalho. São exercícios de verdadeiro ou falso, preencher lacunas ou excluir a palavra que não foi dita. 
Estou ciente que outras mídias como o computador, tablets, smartphones, com acesso à internet são excelentes ferramentas de trabalho, no entanto, os utilizo apenas ocasionalmente, através de programas interativos e jogos no computador. Não utilizo as demais formas de mídia, pois não tenho tempo para cumprir o conteúdo programático e realizar atividades em tablets ou smartphones.

A informante inicia dizendo que acredita ser importante o uso dos equipamentos uma vez que pode trazer a prática para a teoria ao mesmo tempo em que a torna mais dinâmica.

A seguir, passa a arrolar os recursos que utiliza, e podemos perceber que são os mais comuns como os CDs de áudio, para fazer atividades de listening (provavelmente os que estão inseridos no livro didático) e para atividades com música. Apesar de, em seu discurso, dizer que o uso das tecnologias traz dinamicidade à prática de ensino, escapa-lhe o fato de esses exercícios serem de preenchimentos de lacunas, de verdadeiro ou falso ou de exclusão de palavras extras das músicas, o que nos mostra que, apesar de toda a teoria científica dizer que a relação do homem com as tecnologias mudou e que a aquisição/aprendizagem de uma língua estrangeira se dá por meio da interação, ainda vemos exercícios puramente estruturais em sala de aula. Isso mostra que, apesar de seu discurso ser de abertura, sua prática ainda é reflexo de suas experiências enquanto aluna, e portanto, mantém prática positivistas.

No terceiro parágrafo, mais uma vez, a professora reforça o fato de estar ciente e consciente de que o uso das tecnologias são importantes, principalmente as mais novas como os computadores, a internet e os celulares de última geração. No entanto, assume que pouco as utiliza, pois essas atividades demandam tempo e é necessário seguir o conteúdo programático e o calendário escolar estabelecido. Afirma que em sua opinião são excelentes ferramentas de trabalho e elenca o uso de jogos e atividades interativas as quais poderiam efetivamente auxiliar no processo de aprendizagem, uma vez que permitem práticas interativas alternativas às atividades de pairwork empregadas em sala de aula. Apesar de reconhecer sua importância, pode-se perceber um professor atrelado ao livro didático, e nesse caso, não pode se dizer que seja por comodidade, mas por burocracia, uma vez que, segundo a informante, o que a detém é o calendário escolar, que deve ser cumprido.

A segunda informante é uma professora de uma escola particular de ensino 
fundamental e médio.

As tecnologias estão presentes desde a entrada dos alunos, que é cadastrada pelas catracas quando estes passam as carteirinhas. É disponibilizada a internet sem fio de alta velocidade em toda a escola. O uso de projetores multimídia e softwares em lousas digitais também são acessíveis. Apesar de utilizarmos a apostila, as lousas auxiliam nosso trabalho na medida em que podemos mostrar aos alunos do que estamos falando, a realidade. Contamos ainda com grupos de discussão no what's app e no facebook para disponibilizar material extra.

Por fim, as opções são várias, todavia, a presença do professor, do lado humano frente à tecnologia, ainda é indispensável para o efetivo uso da tecnologia em sala de aula.

A segunda informante arrola todas as formas de uso das tecnologias em sala de aula. Apesar de a escola em questão utilizar as apostilas, podemos perceber uma abertura maior com relação as escolhas de material, bem como a possibilidade de uso das tecnologias em benefício das aulas. A lousa digital é usada em auxílio do professor e não como atividade extra, o que acontece em muitas escolas. Aos alunos, é permitido o uso da internet wireless e as redes sociais são transformadas em ferramentas de discussão e disponibilização de material extra, ou seja, ampliando a visão do aluno que não ficará somente preso ao seu livro didático. No entanto, pelo seu relato, as atividades são somente de consulta ou de disponibilização de material, e considerando todo esse aparato tecnológico disponível, poderiam ser feitas atividades diversificadas, que aguçassem a curiosidade dos alunos ou que despertassem seu senso crítico.

Outro ponto que devemos chamar a atenção é para a conclusão da informante. Ela afirma que, apesar das máquinas serem grandes auxiliadoras do trabalho do professor, é a presença deste como mediador, como facilitador e como aquele que, apesar de todas as ferramentas disponíveis, transmitirá o saber. O professor continua a ser a autoridade, o responsável por guiar a utilização dessas tecnologias.

A terceira informante é uma professora de uma escola estadual de ensino fundamental e médio.

O uso da tecnologia é essencial e indispensável nas escolas nos dias atuais. Ele torna o ensino mais dinâmico e os alunos mais interessados. É quase que impossível não usá-la, por mais simples que seja. 
Para trabalhar a parte auditiva, usamos o CD player ou até mesmo o celular. Para pesquisar o vocabulário é muito comum os alunos utilizarem seus próprios celulares, e isso facilita muito o nosso trabalho, principalmente com relação à tradução, pois, o torna mais rápido. É raro ver algum aluno usando o dicionário. Também temos hoje a lousa digital e a sala de informática.

Porém, encontramos vários obstáculos para o uso dos recursos tecnológicos. A velocidade da internet não é compatível, falta ferramentas como cabos, benjamim, e muitas vezes esses equipamentos estão queimados, resultados do mau uso por parte das pessoas envolvidas, mas, se usados corretamente, poderiam colaborar de forma significativa para o ensino e aprendizagem nas escolas públicas.

A informante três, assim como a informante um, inicia sua fala afirmando que o uso das tecnologias em sala de aula é essencial e indispensável nos dias atuais, e justifica esse comentário dizendo que as aulas se tornam mais dinâmicas com seu uso e os alunos mais interessados.

Com relação aos aparatos tecnológicos utilizados em sala, destaca o CD player, para as atividades de áudio ou o celular, uma vez que muitas vezes é mais fácil baixar uma música pela internet e ouvi-la pelo celular do que ter que a buscarem em CDs ou pen drives. Outro ponto o qual devemos salientar é o fato de o uso dos dicionários, segundo a informante, estar sendo substituído pelos dicionários online ou pelas ferramentas de tradução da internet. No entanto, vemos mais uma vez um escape, uma falha, quando ela completa "principalmente com as atividades de tradução", o que nos mostra mais uma vez, que, apesar da tecnologia estar presente em sala, a forma como é utilizada ainda se baseia em exercícios estruturais e de tradução, o que nos remete ao método de Gramática e Tradução, precursor dos métodos de ensino de língua estrangeira e que muito foi utilizado para o ensino do Latim. Dessa forma, vemos o moderno convivendo com o antigo e dá-se o conflito do sujeito heterogêneo e que busca sua completude. De que forma é possível ter êxito quando duas práticas tão antagônicas tentam conviver?

Somado a isso, aparecem as dificuldades. Apesar de a escola ter uma lousa digital e um laboratório de informática, não é tão fácil assim utilizá-los, pois, a velocidade da internet não é compatível com a tecnologia, e muitas vezes, aqueles que deveriam zelar pelo bom uso dos equipamentos para tornar suas aulas mais dinâmicas ou fazer com que a escola pública seja um exemplo, acabam por destruir ou não cuidar 
do que têm, o que podemos inferir pela afirmação de que faltam equipamentos ou os mesmos estão queimados, o que seria resultado do mau uso por parte "das pessoas envolvidas", podendo ser os próprios professores, os funcionários da escola ou os alunos.

A informante conclui dizendo que, se esses equipamentos fossem utilizados corretamente, poderiam contribuir significantemente para o ensino em sala de aula, e completo dizendo que, se os professores conseguissem se libertar dos exercícios estruturais e (des)construíssem o uso dessas tecnologias, sejam livros ou CDs de áudio, lousas interativas ou computadores, o ganho dos alunos seria infinitamente maior.

\section{CONSIDERAÇÕES FINAIS}

Podemos concluir que, nos três trechos analisados, as informantes afirmam que as tecnologias são importantes ferramentas de auxílio para o ensino e que existe uma necessidade real de seu uso. Esse discurso é pautado no discurso científico que, segundo Coracini (2007, p. 210) "é legitimado pelas pesquisas científicas que o embasam e assume no imaginário do professor, valor de verdade, e, como decorrência, por meio de um processo de naturalização, ganha um status de naturalidade" o que, portanto, contribui diretamente para a formação identitária desse professor, que se pauta na verdade da ciência, das teorias linguísticas que são disseminadas por meio de cursos e livros, para justificar suas escolhas com relação ao uso das tecnologias e a sua prática de ensino. De acordo com Mascia (2002, p. 72), "há uma relação muito forte entre poder (ideologia), verdade e progresso, entendido como uma incessante busca da verdade (especialmente no campo da ciência), sempre e inevitavelmente permeada por relações de poder."

Não postulamos aqui que o uso das tecnologias seja a solução para os problemas de ensino/aprendizagem, uma vez que, os estudos atuais de Linguística Aplicada apontam para o fato de não haver um método científico ideal, pois, se considera o homem um ser heterogêneo e, portanto, individual, e cada indivíduo aprenderá um idioma a sua maneira, levando em consideração fatores sócio-histórico-econômicobiológico-culturais na formação desse sujeito. Concordando com Bertoldo (2003 p.125), o discurso científico acaba por considerar "monoliticamente a teoria, como um discurso que promete a completude, via domínio dessa teoria que tudo soluciona." Assim, acredita-se estar fazendo a "articulação entre teoria e prática de maneira que a ela caiba 
preencher a lacuna entre o conteúdo específico (linguístico e metalinguístico) e o conteúdo pedagógico (didático e metadidático)". O discurso de solução aparece como mitificação, um mito, que surge na sociedade e que é construído pelos discursos que o legitimam e que o tornam ilusório do preenchimento da completude do sujeito. No entanto, acreditamos e ressaltamos que o uso das tecnologias auxilia o professor como ferramenta que pode tornar o trabalho de interação mais eficaz, os exercícios mais dinâmicos e com efeito de realidade. Para tanto, temos que saber utilizar essas tecnologias de forma comunicativa, sociointeracional, como utilizamos a nossa língua no dia a dia, como forma de sermos e vivermos em sociedade, como um construto social. Ao professor cabe (des)construir o uso dessas ferramentas para que seja ultrapassado o domínio do estrutural, do positivismo e para que o pós-moderno seja efetivamente consolidado nas práticas de ensino.

O conflito do professor não se apresenta mais como o medo de ser substituído pela máquina ou a incerteza quanto à eficácia do uso das tecnologias como em 1997 (CORACINI, 2007). O seu conflito agora é sair do conforto da Torre de Marfim, ou seja, dos exercícios estruturais que ainda persistem em aparecer, para a Torre de Babel, ou seja, a abertura para as novas práticas pedagógicas, novas experiências, além de deixar de ser o centro para dar voz ao aluno, passar a ser facilitador de um processo de aprendizagem que inicia e termina no próprio aluno. A tecnologia não cria ambientes que prescindem do professor, ao contrário, é importante que o professor tome para si a tarefa de projetar o material didático, desconstruindo o positivismo e adequando a pedagogia de ensino às necessidades dos alunos. $\mathrm{O}$ que, na verdade, a tecnologia pode agregar ao professor, é o uso de novos saberes à prática educacional, proporcionandolhe uma maior capacidade crítica de sua ação pedagógica e um leque maior de possibilidades na busca dos interesses de seus alunos. A educação como um todo, o trabalho docente e a relação professor-aluno estão sendo reconfigurados.

Dessa forma, concluímos afirmando que o discurso do professor de língua estrangeira sobre o uso de tecnologias em sala de aula é marcado pela legitimação da verdade científica e teórica, o que constitui sua parte dominante, pois, relaciona-se diretamente com a constituição de sua identidade, a qual se estabelece por meio dos interdiscursos que a permeiam e das relações de poder que dela resultam. 


\section{REFERÊNCIAS}

AUTHIER-REVUZ, J.; Palavras incertas: as não coincidências do dizer. Trad. Cláudia R. C. Pfeiffer et. al. Campinas-SP; Editora da UNICAMP, 1998.

BERTOLDO, E. S.; O discurso pedagógico da linguística aplicada. In: CORACINI, M. J.; BERTOLDO, E. S.; O desejo da teoria e a contingência da prática: discursos sobre e na sala de aula (língua materna e língua estrangeira). Campinas, SP: Mercado das Letras, 2003.

CARDOSO, S. H. B.; Discurso e ensino. Belo Horizonte: Autêntica/ FALE-UFMG, 2005.

CORACINI, M. J.; O discurso da linguística aplicada e a questão da identidade: entre a modernidade e a pós-modernidade. In: CORACINI, M. J.; BERTOLDO, E. S.; O desejo da teoria e a contingência da prática: discursos sobre e na sala de aula (língua materna e língua estrangeira). Campinas, SP: Mercado das Letras, 2003.

A celebração do outro: arquivo, memória e identidade: línguas (materna e estrangeira), plurilinguismo e tradução. Campinas, SP: Mercado das letras, 2007.

LEFFA, V. J. Metodologia do ensino de línguas. In: BOHN, H. ; VANDRESSEN, P. Tópicos de linguística aplicada: o ensino de línguas estrangeiras. Florianópolis: UFSC, 1988. p. 211-231.

MASCIA, M. A. A.; Investigações discursivas na pós-modernidade: uma análise das relações de poder-saber do discurso político educacional de língua estrangeira. Campinas, SP: Marcado das Letras, São Paulo, FAPESP, 2002.

PAIVA, V. L. M; O uso da tecnologia no ensino de línguas estrangeiras: breve retrospectiva histórica (no prelo) http://www.veramenezes.com/publicacoes.html

Linguagem e aquisição de segunda língua na perspectiva dos sistemas complexos. In: BURGO, V. H.; FERREIRA, E. F.; STORTO, L. J. (org.). Análise de textos falados e escritos: aplicando teorias. Curitiba: CRV, 2011.

\section{A AUTORA}

Michele Ester de Moura Campos Furlan é doutoranda em Letras na Universidade Federal de Mato Grosso do Sul e bolsista da Capes (2014-2018). Mestre pela mesma Instituição (2014), possui graduação em Turismo pela Pontifícia Universidade Católica de Campinas (2002) e cursa graduação em Letras (Português/Inglês) na Unicesumar. Faz parte do grupo de pesquisa "Estudos da Língua Falada", atuando principalmente nos seguintes temas: Linguística Aplicada, Língua Inglesa, Análise da Conversação e Marcadores Conversacionais. Atualmente, vem desenvolvendo pesquisas em dialetologia e semântica

E-mail: michele-furlan@hotmail.com 
M.E.M.C.Furlan/ Pesquisas em Discurso Pedagógico 2015.1 